\title{
Hamster Lung Carcinoma
}

National Cancer Institute

\section{Source}

National Cancer Institute. Hamster Lung Carcinoma. NCI Thesaurus. Code C134991.

Carcinoma arising from the lung and occurring in a hamster. 